\title{
THE RESULTS OF SELECTION AND BREEDING SELECTION AIMED AT IMPROVING THE BIOLOGICAL INDICATORS OF SEX-MARKED SILKWORM BREEDS
}

\author{
Elena Alekseevna Larkina \\ Senior Researcher at the Laboratory of "Genetics and Selection of Silkworms" of the Scientific Research \\ Institute of Sericulture, Tashkent, Uzbekistan \\ Nigora Komoliddinovna Abdikayumova \\ Independent Researcher, Department of the Sericulture and Mulberry Growing, \\ Tashkent State Agrarian University, Tashkent, Uzbekistan \\ Akhmad Bakievich Yakubov \\ Doctor of Biological Sciences, Professor, Head of the Laboratory "Genetics and Selection of Silkworms" \\ of the Scientific Research Institute of Sericulture, Tashkent, Uzbekistan
}

Article DOI: https://doi.org/10.36713/epra4059

\begin{abstract}
The article presents the results of research on selection and breeding selection aimed at improving the biological indicators of sex-marked silkworm breeds. The improvement of biological indicators of silkworm breeds marked by gender with the color of green is achieved by carrying out selection and breeding selection, which leads to an increase in the viability of caterpillars and silkworm cocoons. The results of the 3-year study showed that breeding work aimed at improving biological indicators marked on the floor by the stage of the silkworm eggs of species C-5 and C-14 allowed us to increase the viability of caterpillars breed $-590,0 \%$ breed C-14 to $90.9 \%$ and silkiness of cocoons breed-5 to $20.3 \%$, species C-14 to $23.7 \%$.
\end{abstract}

KEYWORDS: Silkworm, gender marking, breeds, selection, caterpillar viability, cocoon silkworm, green color.

\section{INTRODUCTION}

One of the major problems of sericulture around the world is the problem of obtaining pure hybrids that are not clogged with purebred material to realize all the advantages of heterocyst. To create pure hybrids, it is necessary to achieve precise separation of the component breeds by gender. This is possible when used in hybridization of sex-labeled rocks at the Greene stage. The gender-marked breeds were created precisely for the purpose of obtaining hybrids in industrial sericulture with $100 \%$ purity of the preparation of grain [1].

Genetic marking of eggs by gender [6] was obtained by coupling autosomal traits with gender under the influence of nuclear radiation. Translocation of part $\mathrm{X}$ of the autosome with the dominant W2 gene, which determines the dark color of the Grena, to the sex chromosome, leads to a clear division of eggs by color, and therefore by gender, and allows you to get pure hybrids that exceed the parent breeds in all indicators.

To achieve maximum heterocyst, hybridization should involve breeds with high productivity indicators. Therefore, breeding selection is carried out with breeds that are components of pure hybrids, aimed at improving, among other things, biological indicators.

\section{MATERIALS AND METHODS}

The work was carried out in 2012-2014 in the laboratory of selection and genetics of the silkworm of the SRIS (Scientific Research Institute of Sericulture) in the framework of the project KHA-8-032. The study used breeds $\mathrm{C}-5$ and $\mathrm{C}-14$ marked by gender by the color of the serous shell of eggs: females have a dark shell color, males C-5-yellow, C-14-brown. 


\section{EPRA International Journal of Research and Development (IJRD)}

Volume: 5 | Issue: 2 | February 2020

The work with the breeds was carried out in accordance with the" Basic methodological provisions of breeding work with silkworms " [3], which were amended taking into account the genetic characteristics of sex-tagged breeds. For example, each family of the breed labeled by type was incubated separately by gender. At the stage of Gren, families with low reproductive indicators, with an incorrect sex ratio, and with a low percentage of Gren recovery were married. At the caterpillar stage, culling was performed in the case of heterogeneous development and low viability of the caterpillars. The analysis of families was carried out on a sample of 30 cocoons (15 females and 15 males). Families with low rates of silkiness, cocoon mass, and silk shell mass were rejected. According to the results of

individual family analysis, cocoons with a large shell, high silkiness, and the characteristic shape of the cocoon for the breed and fine grain were selected for the preparation of masonry source material. The best individuals were crossed with the best ones using the outbreeding method. The remaining cocoons after selection were used for the preparation of super-elite and hybrid Grena.

\section{RESULTS AND DISCUSSION}

Every year, 25-30 families of each studied breed were fed. Their biological indicators are shown in table 1.

Table 1

Biological indicators and coefficients of variation studied breeds by year

\begin{tabular}{|c|c|c|c|c|c|c|c|c|c|}
\hline \multirow{2}{*}{ Breeds } & \multirow{2}{*}{ Year } & \multicolumn{2}{|c|}{$\begin{array}{c}\text { Viability of } \\
\text { caterpillars, \% }\end{array}$} & \multicolumn{2}{|c|}{ Cocoon weight, g } & \multicolumn{2}{|c|}{$\begin{array}{l}\text { The weight of } \\
\text { the shell, mg }\end{array}$} & \multicolumn{2}{|c|}{ Silkiness, \% } \\
\hline & & $\bar{X} \pm \mathbf{S} \bar{x}$ & $\mathrm{C}_{\mathrm{v}}$ & $\bar{X} \pm \mathbf{S} \bar{x}$ & $\mathrm{C}_{\mathrm{v}}$ & $\bar{X} \pm \mathbf{S} \bar{x}$ & $\mathbf{C}_{\mathrm{v}}$ & $\bar{X} \pm \mathbf{S} \bar{x}$ & $\mathrm{C}_{\mathrm{v}}$ \\
\hline \multirow{3}{*}{$C-5$} & 2012 & $91,8 \pm 1,2$ & 15,1 & $1,53 \pm 0,02$ & 4,1 & $333 \pm 4,4$ & 6,9 & $20,8 \pm 0,2$ & 5,2 \\
\hline & 2013 & $92,5 \pm 2,2$ & 14,9 & $1,54 \pm 0,02$ & 4,8 & $326 \pm 3,4$ & 5,7 & $21,2 \pm 0,17$ & 4,4 \\
\hline & 2014 & $90,0 \pm 2,0$ & 14,0 & $1,50 \pm 0,02$ & & $320 \pm 3,2$ & 5,1 & $20,3 \pm 0,2$ & 4,2 \\
\hline \multirow{3}{*}{ C-14 } & 2012 & $92,5 \pm 3,3$ & 14,8 & $1,48 \pm 0,21$ & 6,6 & $346 \pm 6,4$ & 48 & $23,6 \pm 0,2$ & 4,5 \\
\hline & 2013 & $91,8 \pm 3,0$ & 15,1 & $1,50 \pm 0,02$ & 6,6 & $360 \pm 3,4$ & 3,4 & $23,8 \pm 0,19$ & 4,5 \\
\hline & 2014 & $90,9 \pm 3,0$ & 15,2 & $1,48 \pm 0,02$ & & $350 \pm 3,5$ & 3,3 & $23,7 \pm 0,2$ & 4,1 \\
\hline $\begin{array}{c}\text { Ipakchi } \\
2(\kappa)\end{array}$ & cp. & $93.5 \pm 2,0$ & 8,5 & $17,8 \pm 0,02$ & 5,0 & $401 \pm 2,7$ & 2,5 & $22,5 \pm 0,2$ & 3,9 \\
\hline
\end{tabular}

As can be seen from table 1 , the viability of caterpillars taken in the work of rocks for three years remained quite high and ranged from $90.0 \%$ to $92.5 \%$. It should be noted that the viability of the tracks of the C-5 and $\mathrm{C}-14$ breeds marked on the floor was somewhat reduced in comparison with the control. Sex-tagged breeds differ from normal breeds by the presence of chromosomal rearrangements in their genomes. Therefore, these breeds are more sensitive to any changes in the conditions of detention. As we know from the research of V. A. Strunnikov [5] in good experimental conditions, the biological characteristics of sex-labeled rocks are at the same level as that of normal material, but in unstable conditions, the material with genetic changes behaves somewhat worse. High coefficients of variation from 14.0 to 15.2 of sex-labeled breeds indicate a large variability in such an indicator as the viability of caterpillars and indicate the possibility of further selection on this basis.

One of the objectives of this study is to increase the silkiness of the studied rocks. For 3 years of practical breeding work, the silkiness of cocoons was raised by $0.1 \%$ in $\mathrm{C}-14$ (Table 1 ).
According to U. N. Nasirillaev [4] silk productivity negatively correlates with the viability of caterpillars and reproductive traits, however, he also points out that selection can lead to changes in the existing relationships between traits with long-term, targeted and intensive selection. Therefore, if there is enough time, it is possible to achieve high silkiness, while maintaining maximum viability and reproductive properties.

In 2012, 2013, and 2014, 10 to 12 families with the best indicators of caterpillar viability and cocoon silkiness were selected from 25-30 families of each breed. From each selected family, 30-50 cocoons with the correct cocoon shape and fine grain were visually selected. All selected cocoons were individually weighed. Cocoons with the best silkiness were left to the tribe. As an example, and in order not to overload the article, table 2 shows the biological indicators of the families and cocoons of the studied breeds selected for the tribe, collected in 2014. 


\section{EPRA International Journal of Research and Development (IJRD)}

Volume: 5 | Issue: 2 | February 2020

Table 2

Biological indicators of the families and cocoons of the studied breeds selected for the tribe (2014)

\begin{tabular}{|c|c|c|c|c|c|}
\hline & \multirow[b]{2}{*}{ Breeds } & \multirow{2}{*}{$\begin{array}{c}\text { Viability of } \\
\text { caterpillars, } \\
\%\end{array}$} & \multicolumn{2}{|c|}{ Average weight } & \multirow[b]{2}{*}{ Silkiness, $\%$} \\
\hline & & & $\operatorname{coc} \theta 0 n=$ & shell mo & \\
\hline \multirow{3}{*}{ C-5 } & raised families & 90,0 & 1,50 & 320 & 20,3 \\
\hline & tribal families & 96,9 & 1,41 & 317 & 22,5 \\
\hline & breeding cocoons & - & 1,42 & 329 & 23,2 \\
\hline \multirow{5}{*}{ C-14 } & raised families & 60,9 & 1,48 & 350 & 23,7 \\
\hline & tribal families & 91,1 & 1,40 & 336 & 24,0 \\
\hline & breeding cocoons & - & 1,40 & 347 & 24,8 \\
\hline & tribal families & 98,4 & 1,58 & 406 & 25,7 \\
\hline & breeding cocoons & - & 1,58 & 408 & 25,8 \\
\hline
\end{tabular}

From table 2, it can be seen that when cocoons were silk-bearing, for example, the C-5 breed had $21.3 \%$ silkiness per tribe, and cocoons with a silkiness of $23.2 \%$ were allowed for papillonage. A similar

selection was carried out in the C-14 breed (Table 2), i.e. the selection intensity was quite high.

This is shown in table 3 . For all three years of research, the selection differential for silkiness was 0.6$1.0 \%$.

Table 3

Selection differential for silkiness of breeds P-5, P-14 by year

\begin{tabular}{|c|c|c|c|c|c|c|}
\hline \multirow{3}{*}{ Breeds } & \multirow{2}{*}{ Year } & \multicolumn{2}{c|}{$\begin{array}{c}\text { Number of cocoons, } \\
\text { pieces }\end{array}$} & \multicolumn{2}{c|}{ Silkiness, \% } & \multirow{2}{*}{ S } \\
\cline { 3 - 7 } & & Total & Selected & Total & Selected & \\
\hline \multirow{3}{*}{ C-5 } & 2012 & 749 & 424 & 21,5 & 22,3 & 0,8 \\
\cline { 2 - 7 } & 2013 & 532 & 320 & 21,5 & 22,5 & 1,0 \\
\cline { 2 - 7 } & 2014 & 531 & 323 & 22,5 & 23,2 & 0,7 \\
\hline \multirow{3}{*}{ C-14 } & 2012 & 534 & 297 & 23,8 & 24,4 & 0,6 \\
\cline { 2 - 7 } & 2013 & 412 & 290 & 23,0 & 23,9 & 0,9 \\
\cline { 2 - 7 } & 2014 & 652 & 396 & 24,0 & 24,8 & 0,8 \\
\hline
\end{tabular}

In total, 1500-2000 cocoons of each breed were individually analyzed during the reporting period. Of these, 800-1100 pieces were allowed before the production of breeding grain, i.e. $60 \%$ of cocoons with the best silkiness. This intensity of selection made it possible to raise the silkiness of the subjects.

The tendency to increase silk-bearing capacity that has been observed for 2 years of selection can be strengthened if the selection continues and intensifies. However, the indicators of silk productivity achieved to date are already comparable with the indicators of the studied breeds presented in the Catalog "Genetic Fund of the world collection of the silkworm of Uzbekistan" [2].

\section{CONCLUSION}

Selection and breeding for 3 years, aimed at improving biological indicators marked on the floor by the stage of the silkworm eggs of species C-5 and C-14, leads to an increase of viability of caterpillars breed -5
$90,0 \%$ breed C-14 to $90.9 \%$ and sulconazole cocoons breed-5 to $20.3 \%$, species C-14 to $23.7 \%$.

\section{REFERENCES}

1. Chernetsova N.T., Zakirova Kh., Kurbanova M., Larkina Ye.A. (1990). Results of selection and breeding work with new silkworm breeds labeled with W2, w3, w5 sex markers. in the book.: "Scientific basis for the development of sericulture in Uzbekistan". Ташкент, pp. 19-22.

2. Daniyarov U.T., Larkina E.A., Yakubov A.B. (2018). Using parthenogenetic clones to improve the quality of silkworm cocoon thread. Moscow, J. "Internauka», №12(46). pp. 49-51.

3. Nasirillayev U.N., Lejenko S.S. (2002). Basic methodological provisions of the breeding of mulberry silkworm (guidance document). Tashkent, $16 \mathrm{p}$.

4. Nasirillayev U.N. (1985). The genetic basis of selection in the silkworm. Tashkent: FAN, pp. 3-50.

5. Strunnikov B.A. (1987). Genetic methods of selection and regulation of sex in the silkworm. Moscow: Agropromizdat, pp. 3-21.

6. Strunnikov B.A., Gulamova L.M. (1969). Artificial regulation of sex in the silkworm. Moscow, Genetics, № 6. pp. 14-15. 